\title{
The application of the improved option parity arbitrage model in SSE 50ETF option
}

\author{
Liu $\mathrm{Xu}^{1}$ \\ ${ }^{1}$ School of Economics and Management Beijing Jiaotong University Beijing, China
}

\begin{abstract}
The SSE 50ETF option is China's first stock index option product launched in 2015. For a number of reasons, the options market can sometimes create arbitrage opportunities. Based on the theory of option parity arbitrage and taking into account the transaction costs, this paper explores effective options arbitrage strategies and practices them. Based on the theory of option parity arbitrage and taking into account the transaction costs, this paper establishes an effective option arbitrage strategy model and puts it into practice. The results show that there are indeed arbitrage opportunities in the market that exceed the risk-free rate of return, but there are not many such opportunities, and there is not much arbitrage space under many opportunities. This is not only the embodiment of high market efficiency, but also the result of taking various transaction costs into full consideration in this paper to ensure the effectiveness of arbitrage.
\end{abstract}

\section{INTRODUCTION}

The option first appeared in the United States in the 1970s. It is a right to buy and sell the underlying asset at a certain time or within a certain period in the future. In essence, the option is a tool to price the right. As a financial instrument with hedging function in the financial market, option era has developed rapidly since The first option product of China -- SSE 50ETF option was listed on February 9, 2015, which also marks the arrival of a new era of hedging in China's securities market.

The literature on 50ETF option arbitrage focuses on the period after 2015. Dong Anqi (2015) used b-S model to calculate the pricing of 50ETF option, compared the calculated results with the market price of option, and analyzed the possible causes of the pricing error. Qian Shensheng (2016) discussed the application of parity arbitrage of European options in the Chinese market. Jinzhong Wang et al. (2018) used parity arbitrage model to explore the arbitrage opportunities and earnings between the two derivative markets of sSE 50 stock index futures and 50ETF options. Xu Tongtong et al. (2018) conducted risk-free arbitrage according to the upper and lower limits of option royalty prices and risk-free arbitrage according to Gamma index.

The above research results show that 50 etf options market in our country there is a risk-free arbitrage opportunities, but after validation of many authors found that 50 etf options market itself is already relatively mature capital market, arbitrage opportunities so there is not much, mainly focused on the specific period, such as callable bull/bear contracts (market volatility is larger) transformation period, the end of a bear market downturn (volume).
According to the characteristics of China's financial markets, on the basis of the principle of no arbitrage, the law of one price and formula of European option parity, give full consideration to all kinds of transaction costs to ensure the effectiveness of arbitrage strategy, for more than a given threshold and poor option price is lower than the given threshold, specific strategy of long and short arbitrage is given respectively, and discussed based on the dividend and 50 etf of Shanghai 50 index tracking deviation on whether there is a greater arbitrage space.

\section{ARbitrage theORY}

The no-arbitrage principle is very important for any option pricing. Arbitrage can be said to be carried out all the time. It enables investors to obtain stable excess returns, which is the primary motivation for many investors to do arbitrage. Arbitrage is conducive to forming a fair price in the market, improving market liquidity, curbing excessive speculation, and returning the option price to its fair value. Therefore, arbitrage itself is an important part of market behavior."

There is often a price balance between the option and its underlying assets and derivatives, but in the process of trading, there will be frequent deviations between the option price and the theoretical value, so as to provide arbitrage opportunities for investors. However, the traditional theoretical model generally does not take into account the impact of the actual trading environment in the derivation of the equilibrium relationship, so the suggested arbitrage opportunities are not fully in line with the reality and need to be further revised.

In addition, financial products in emerging markets are often considered to be inefficient, and the range and frequency of pricing deviations are larger and higher than

\footnotetext{
*Corresponding author: 19120497@bjtu.edu.cn
} 
those in mature markets. As a new financial derivative product in emerging markets, 50ETF options are generally considered to have some risk-free arbitrage income opportunities.

\section{THE ARBITRAGE MODEL}

\subsection{Basic model}

Based on the principle of no arbitrage in the financial market, in an ideal market environment, regardless of transaction costs, bid-ask spreads, securities borrowing costs or margin costs, there should be the current value of future $\mathrm{X}$ cash $=$ to buy and hold one share + to buy one put option - to sell one call option, which can be expressed as:

Based on the principle of no arbitrage in the financial market, in an ideal market environment, regardless of transaction costs, bid-ask spreads, securities borrowing costs or margin costs, there should be the current value of future $\mathrm{X}$ cash $=$ to buy and hold one share + to buy one put option - to sell one call option, which can be expressed as:

$$
X e^{-r(T-t)}=S_{t}+P-C \ldots \ldots
$$

Where $\mathrm{C}$ and $\mathrm{P}$ are the prices of call options and put options, is the price of the underlying asset at time $t, X$ is the strike price, $\mathrm{T}$ is the strike date, and $\mathrm{r}$ is the risk-free interest rate. Further, the parity formula between European call option (call option) $\mathrm{C}$ and put option (put option) $\mathrm{P}$ is as follows:

$$
C-P=S_{t}-X e^{-r(T-t)} \ldots
$$

If the option price deviates from the above formula, an arbitrage can be obtained.

Formula (2) adopts continuous compound interest, while in the real market, multi-period compound interest is generally adopted. Therefore, the above formula can be modified as follows: follows:

$$
C-P=S_{t}-X(1+r)^{-(T-t)} \ldots \ldots
$$

Definition of price difference d:

$$
d=C-P-S_{t}+X(1+r)^{-(T-t)} \text {. }
$$

According to formula (4), when $d>0$, we can carry out long arbitrage, that is, sell call option $\mathrm{C}$, buy put option $\mathrm{P}$ and spot $S_{t}$, and hold until the maturity date to deliver, then we can obtain arbitrage, the amount of arbitrage is:

$$
R_{1}=d(1+r)^{(T-t)}=X+\left(C-P-S_{t}\right)(1+r)^{(T-t)} \ldots
$$

When $\mathrm{d}<0$, short arbitrage can be carried out, call option $\mathrm{C}$ can be bought, put option $\mathrm{P}$ can be sold and spot $S_{t}$ can be shorted at the same time, the cash balance can be invested without risk, and the arbitrage can be obtained by holding the delivery at maturity and returning $S_{t}$. The amount of arbitrage is:

$$
R_{2}=-d(1+r)^{(\tau-t)}=-X+\left(P+S_{t}-C\right)(1+r)^{(\tau-t)}
$$

In Equation (5) and (6), data of $\mathrm{X}, \mathrm{P}, S_{t}, \mathrm{C}$ and (T-t) are relatively easy to obtain. For the risk-free interest Rate $\mathrm{R}$, Shanghai Interbank Offered Rate (Shibor) is selected as the reference data in this paper. Table 1 is the Shibor variety interest rate table on June 15, 2020:

TABLE I. ShIBOR VARIETy RATE TABLe, 15 June 2020

\begin{tabular}{|c|c|}
\hline Varieties & Interest rate (\%) \\
\hline $\mathrm{O} / \mathrm{N}$ & 1.477 \\
\hline $1 \mathrm{~W}$ & 1.855 \\
\hline $2 \mathrm{~W}$ & 1.79 \\
\hline $1 \mathrm{M}$ & 1.916 \\
\hline $3 \mathrm{M}$ & 1.987 \\
\hline $6 \mathrm{M}$ & 2.03 \\
\hline $9 \mathrm{M}$ & 2.141 \\
\hline $1 \mathrm{Y}$ & 2.207 \\
\hline \multicolumn{2}{|c|}{ Data source: Website of National Inter-Bank Lending Center } \\
\hline
\end{tabular}

In the actual arbitrage process, the interest rate of the corresponding period should be selected according to the expiration time of the option. For example, if on June 15 we find arbitrage opportunities on a 50ETF option expiring in July, we should choose the one-month Shibor, $\mathrm{r}=1.916 \%$. If we find arbitrage opportunities on a $50 \mathrm{ETF}$ option expiring in September, we should choose the threemonth Shibor, $r=1.987 \%$. And so on.

\subsection{Model with transaction costs}

In the actual process of obtaining arbitrage, transaction costs must also be considered, such as transaction costs, interest costs of securities lending. At the same time, it is necessary to consider whether the arbitrage rate of return reaches or exceeds the lowest rate of return expected by arbitrageurs once the arbitrage conditions are triggered. In response to these, arbitrage strategies must be adjusted. Calculate the transaction cost of each strategy, calculate the corresponding arbitrage rate of return $\pi$, and compare the arbitrageur's expected rate of return $\pi_{\Omega}$. The expected rate of return is generally higher than the current risk-free rate of return:

$$
\pi_{e}>\frac{r(T-t)}{365}
$$

Only when the arbitrage rate of return $\pi>\pi_{-}$e, the implementation of the corresponding arbitrage strategy is meaningful.

\subsubsection{Transaction costs and arbitrage strategies under the long strategy}

According to formula (4), when $\mathrm{d}>0$, a long strategy can be implemented for arbitrage. That is, the call option $\mathrm{C}$ is sold, the put option $\mathrm{P}$ and the spot $S_{t}$ are bought, which involve the transaction cost of buying spot assets and the transaction cost of buying and selling options.

The 50ETF discussed in this article is an on-exchange fund, so there are no subscription and redemption fees. Its transaction costs are mainly transaction commissions charged by brokers, without stamp duty. However, the 
fees charged by various brokerage companies are different Generally, they are charged at $0.025 \%$ to $0.08 \%$ of the transaction amount and 5 yuan when they are less than 5 yuan. Therefore, the transaction cost can be set to $0.05 \%$ and charged in both directions.

In addition to the price of the option itself, the transaction cost of option products also includes commissions charged by brokers, handling fees charged by exchanges, transaction settlement fees charged by China Clearing Corporation, and exercise fees. In addition, because the 50ETF spot held in the strategy can be used as a cover to open a position, the call option sold in this strategy does not need to consider the margin.

Other specific transaction costs are as follows:

(1) Brokerage commission: it is charged by brokerage companies. This fee is different for different brokerage companies. There are 5 yuan, 10 yuan, and a minimum of 2 yuan. In recent years, the competition between brokerage firms has made the current commission level generally low. This article is charged at 5 yuan per sheet;

(2) Transaction handling fee: charged by the exchange. If the subject of the contract is an ETF, it will be charged at 1.3 yuan/piece, and it will be charged bilaterally. There is no such fee for exercise;

(3) Transaction settlement fee: charged by the China Clearing Corporation, 0.3 yuan per contract for ETFs, and charged bilaterally;

(4) Exercise settlement fee: charged by China Clearing Corporation, and the contract subject is 0.6 yuan per ETF to the exerciser.

Combining formula (5) and considering the above costs, the profit of the long arbitrage strategy considering various costs is:

$$
\begin{array}{r}
R_{1}^{\prime}=10000 R_{1}-10000 S_{t} * 0.05 \% * 2-5 * 2-1.3 * 2 \\
-0.3 * 2-0.6=10000 R_{1}-10 S_{t}-13.8 \ldots(7)
\end{array}
$$

If $R_{1}^{\prime}>0$, it means there is an arbitrage opportunity at this time:

\subsubsection{Transaction costs and arbitrage strategies under the short strategy}

According to formula (4), when $\mathrm{d}<0$, a short position strategy can be implemented for arbitrage. That is, the call option C is bought, the put option P is sold, and the stock $\mathrm{S} \mathrm{t}$ is sold at the same time. But in reality, in addition to the option transaction handling fee, transaction settlement fee, and exercise settlement fee in the long strategy, it is also necessary to consider the cost of securities lending, the margin for securities lending and selling of stock, and the margin cost of selling put options. Because the margin must be kept in the account and only money fund related transactions can be carried out, the money fund rate of return can be approximated as a risk-free rate of return. The required margin and cost are calculated as follows:

(1) Margin required to sell options

According to Article 15 of the "Shanghai Stock Exchange and China Securities Depository and Clearing Co., Ltd. Stock Option Pilot Risk Control Management Measures", if the subject of the contract is an Exchange
Traded Fund (ETF), the formula for calculating the opening margin for each contract is:

Put option obligation position opening margin $=\min [$ pre-contract settlement price $+\max$ $(12 \% \times$ contract target previous closing price-put option virtual value, $7 \% \times$ strike price), exercise price] $\times$ contract unit, where, Put option virtual value $=\max$ (the previous closing price of the contract subject-the exercise price, 0 )

Use $M_{1}$ to represent the margin required to sell the put option. Considering the violent price fluctuations in option transactions, the margin amount is constantly adjusted. Therefore, we enlarge the above formula and replace min with max, which can be expressed as:

$M_{1}=\max \left\{P+\max \left\{12 \% * S_{t}-\left[S_{t}-X\right]^{+}, 7 \% * X\right\}, X\right\}$.

Income during the period of the margin occupation:

$$
E_{1}=M_{1} *(1+r)^{(\tau-t)}-M_{1} \ldots \ldots
$$

(2) Securities lending and margin

According to Article 39 of the "Shanghai Stock Exchange Margin Trading Implementation Rules (Revised in 2019)", when investors sell securities, the ratio of securities lending margin shall not be less than $50 \%$. Therefore, the securities margin M_2 can be expressed for:

$$
M_{2}=50 \% * \max \left\{S_{0}, S_{t}\right\}_{\ldots} \ldots
$$

Among them, $S_{0}$ represents the price when buying, $S_{t}$ represents the current price. Income during the period of the margin occupation:

$$
E_{2}=M_{2} *(1+r)^{(\tau-t)}-M_{2} \ldots \ldots
$$

The securities lending interest rate is set to $R$, regardless of the cost of overdue and default, the securities lending cost is:

$$
C_{l}=S_{t} *(1+R)^{(T-t)}-S_{t}
$$

Combining formula (6) and considering the above costs, the short arbitrage strategy income considering all costs is obtained: :

$R_{2}^{\prime}=10000\left(R_{2}-S_{\mathrm{t}} * 0.05 \% * 2+E_{1}+E_{2}-C_{l}\right)-5 * 2-1.3 * 2$
$-0.3 * 2-0.6=10000\left(R_{2}+E_{1}+E_{2}-C_{l}\right)-10 S_{t}-13.8$

If $\mathrm{R} \_2^{\wedge^{\prime}}>0$, it means there is an arbitrage opportunity at this time.

\subsubsection{Strategy Test}

Taking the June 15, 2020 date rights market as an example, Table 2 shows the closing price of options expiring in July on that day to detect whether there is a spread $d$ in the arbitrage space. The closing price of the SSE 50ETF on the day is 2.847 . 
TABLE II. THE PRICE AND SPREAD OF 50ETF OPTIONS EXPIRING IN JULY ON JUNE 15, 2020

\begin{tabular}{|c|c|c|c|}
\hline $\begin{array}{c}\text { Strike } \\
\text { price } \\
\mathbf{X}\end{array}$ & $\begin{array}{c}\text { Subscription } \\
\text { price C }\end{array}$ & Put price P & d \\
\hline 2.65 & 0.183 & 0.0196 & -0.0377 \\
\hline 2.7 & 0.1397 & 0.029 & -0.0405 \\
\hline 2.75 & 0.1026 & 0.0413 & -0.04 \\
\hline 2.8 & 0.0717 & 0.0614 & -0.0411 \\
\hline 2.85 & 0.047 & 0.0895 & -0.044 \\
\hline 2.9 & 0.0294 & 0.1173 & -0.0394 \\
\hline 2.95 & 0.0176 & 0.1555 & -0.0395 \\
\hline 3 & 0.0108 & 0.1979 & -0.0388 \\
\hline 3.1 & 0.0042 & 0.2918 & -0.0394 \\
\hline
\end{tabular}

Because $d<0$, short arbitrage strategy is implemented. Select an option portfolio with an exercise price of 2.85 to execute the arbitrage strategy. When buying a call option and selling a put option, the deposit is 28500 yuan. When the securities lending sold 10,000 50ETF spot, the deposit was 14235 yuan, and the securities lending interest rate was $\mathrm{R}=8.35 \%$ (the securities lending interest rate of CITIC Securities on June 15). The risk-free interest rate $\mathrm{r}=1.916 \%$. Substituting various data into formula (13):

$$
\begin{gathered}
R_{2}^{\prime}=-10000\left[d(1+r)^{(T-t)}+\left(M_{1} *(1+r)^{(T-t)}-M_{1}\right)+\right. \\
\left.\left(M_{2} *(1+r)^{(T-t)}-M_{2}\right)-\left(S_{t} *(1+R)^{(T-t)}-S_{t}\right)\right] \\
-10 S_{t}-13.8=275.16
\end{gathered}
$$

That is, after deducting various costs, the strategy can arbitrage 275.16 yuan, the investment period is 40 days, the return is $0.644 \%$, and the annualized rate of return is $5.88 \%$.

\section{SUMMARY}

This paper calculates the various transaction costs in the process of option parity arbitrage, and explores a model that can further ensure the effectiveness of the arbitrage strategy. Through the practice of the revised strategy, it is found that there are arbitrage opportunities in the market that exceed the risk-free rate of return, but there are not many such arbitrage opportunities, and there is not much room for arbitrage under many opportunities. This is not only a manifestation of higher market efficiency, but also the result of this article fully considering various transaction costs to ensure the effectiveness of arbitrage.

The previous literature usually does not consider the time cost and benefits of the margin. This article innovatively considers the time value of the margin to maximize revenue, and fully considers the two transaction costs when locking the revenue, and enlarges the amount of margin to make the strategy more effective. However, the deficiency is that both options and margin are dynamic changes, which is not fully considered in this paper. In addition, the various taxes and fees generated in the transaction process are not included in the cost, but because the taxes and fees are relatively low, they have little effect on the results of the arbitrage strategy.

If further consideration is given to dividends and $50 \mathrm{ETF}$ tracking deviation factors, there may be more room for arbitrage, especially from the perspective of deviation, which can be analyzed and found from data such as the deviation of a single day exceeding a certain level and the change level of deviation of a single day Effective arbitrage strategy, but this method also has certain shortcomings: although the underlying asset of $50 \mathrm{ETF}$ options is 50ETF instead of SSE 50 index, in the actual trading process, it is not ruled out that investors have generally paid attention to the difference between SSE 50 index and 50 ETF. As a result, the arbitrage opportunity is reduced or even non-existent, and even if such an arbitrage opportunity exists, it will be affected by liquidity.

\section{REFERENCES}

1. Huiming Zhang, Junzo Watada, "An analysis of the arbitrage efficiency of the Chinese SSE 50ETF options market", International review of economics and finance, vol. 59, pp.474-489, January 2019.

2. Jinzhong Wang, Hao Kang, Fei Xia \& Guowei Li, "Examining the Equilibrium Relationship between the Shanghai 50 Stock Index Futures and the Shanghai 50 ETF Options Markets", Emerging Markets Finance and Trade, vol. 54, pp.2557-2576, November 2018.

3. Surong You, "On the No-arbitrage Principle and Option Pricing in a Fuzzy Market", Journal of DongHua University, vol. 23, pp.60-63, March 2006.

4. Zhang Tianfeng, Zhu Jiaming, "Research on SSE 50ETF Option Pricing Based on B-S Model", Journal of Guiyang University (Natural Science Edition), vol. 11, pp.40-43, February 2016.

5. Liu Jiaxin, Cai Xiaojuan, Ding Ruichang, "European option pricing model and trading strategy", Digital User, vol. 24, pp.201, April 2018.

6. Qian Shensheng, Zhu Wei, "The application of option parity arbitrage in the Chinese market", Value Engineering, vol.35, pp.14-15. January 2016.

7. Xu Tongtong, Wang Susheng, Peng Ke, "Research on SSE 50ETF Option Risk Management and Arbitrage Strategy", Journal of North China Electric Power University (Social Science Edition), vol.111, pp.4754, January 2018.

8. Chen Yuanzhi, Su Haifeng, "Tracking error analysis and cause analysis of SSE 50ETF", Industrial Technology Economy, vol.168, pp.149-152, October 2007.

9. Chen Yuanzhi, "An Empirical Study on the Tracking Error of SSE 50ETF", Technoeconomics and Management Research, 2007, vol.155, pp. 6-9, June 2007.

10. Liu Dehong, Huang Zhenhuan, Chen Zongzhi, "Research on the Market Efficiency of SSE 50ETF Stock Options", Journal of Beijing Jiaotong University (Social Science Edition), vol.18, pp.48-56, January 2019. 
11. Shan Lei, Zheng Bairu, "Research on risk-free arbitrage strategy of stock options in my country", Price Theory and Practice, vol.379, pp.140-142, January 2016.

12. Xian Jingchen, Liu Qing, "Research on arbitrage path and risk countermeasures of 50ETF option on
China's Shanghai Stock Exchange", Journal of Chongqing Normal University (Philosophy and Social Sciences Edition), vol.172, pp.76-85, May 2016. 